\title{
The Impact of Parity and Duration of Biotin Supplementation on White Line Disease Lameness in Dairy Cattle
}

\author{
C. J. Pötzsch, ${ }^{\star}$ V. J. Collis (née Hedges), † R. W. Blowey,‡ \\ A. J. Packington, $\S$ and L. E. Green* \\ *Ecology and Epidemiology Group, Department of Biological Sciences, \\ University of Warwick, Coventry, UK \\ †ADAS, Rosemaund, Preston Wynne, Hereford HR1 3PG, UK \\ $\ddagger$ Wood Veterinary Group, St. Oswalds Road, Gloucester, UK \\ $\S R o c h e$ Vitamins (UK) Ltd., Heanor Gate, \\ Heanor, Derbyshire, UK
}

\section{ABSTRACT}

A field study was conducted to examine effects of oral biotin supplementation for up to 18 mo on risks of lameness in dairy cows. The study included a total of 900 cattle from five dairy farms in Gloucestershire, southwest U.K., in a within-herd randomized control trial. The data from this trial were used in this paper to investigate the impact of parity and duration of supplementation with oral biotin at $20 \mathrm{mg} / \mathrm{d}$ on white line disease (WLD) lameness. Analysis of the data indicated that WLD increased with increasing parity independent of biotin supplementation from approximately two cases per 100 cow years in primiparous cows to 15.5 cases per 100 cow years in all multiparous cows, but up to 47.7 cases per 100 cow years for cows in parities $\geq 5$. Supplementation with biotin reduced WLD lameness by $45 \%$ in multiparous cows down to 8.5 cases per 100 cow years, whereas the effect of biotin supplementation in primiparous cows was not significant. Although numerical reductions in WLD lameness were observed for shorter periods of supplementation, a supplementation length of at least 6 mo was required to significantly reduce the risk of WLD lameness in multiparous cows. The effect of biotin supplementation in reducing lameness has potential impact for both animal welfare and farm economics.

(Key words: white line disease lameness, biotin supplementation, survival analysis, parity)

Abbreviation key: HR = hazard ratio, $\mathbf{W L D}=$ white line disease.

\section{INTRODUCTION}

In 1997 the Farm Animal Welfare Council (FAWC, 1997) stated that the high level of lameness on dairy

Received October 8, 2002.

Accepted March 14, 2003.

Corresponding author: L. Green; e-mail: laura.green@warwick. ac.uk. farms in the United Kingdom was unacceptable. In the UK, the annual incidence of lameness has been estimated at 55 (Clarkson et al., 1996) and 68.9 (Hedges et al., 2001) cases per 100 cow years. Lameness in dairy herds is a considerable problem across the world. In Europe, Distl (1995) reported that over half the dairy cows in European countries were affected by foot and leg problems. In Wisconsin and Minnesota the prevalence of lameness was estimated to be 14 to $17 \%$ (Wells et al., 1993).

In 1995, lameness was considered the third most expensive health problem in UK dairy herds, only surpassed by fertility problems and mastitis. The cost of treating an affected cow was estimated to be US $\$ 240$ (£150) (Kossaibati and Esslemont, 1995). Loss of income also occurs because cow productivity declines well before the onset of clinical signs and continues after a lame cow has been diagnosed and treated (Guard, 1997; Green et al., 2002). Green et al. (2002) reported a reduction in milk yield from up to 4 mo before to 5 mo after an episode of lameness was diagnosed and treated, with lame cows producing approximately $360 \mathrm{~kg}$ less milk, a further net cost of approximately US $\$ 48$ (£30) per affected cow, assuming a net income of US $\$ 0.14$ (£0.09)/ kg milk.

Biotin, a B-group vitamin, is an important factor for the development of strong hoof horn. It is involved in the differentiation of epidermal cells, and in the production of keratin and intracellular cementing substance (Mülling et al., 1999). In adult ruminants, biotin supplementation leads to improved hoof health. Distl and Schmid (1994) demonstrated a significant reduction in claw disorders in a clinical trial of 56 cows that were supplemented with $20 \mathrm{mg} / \mathrm{d}$ biotin for $11 \mathrm{mo}$. Other studies have demonstrated a reduction in lameness and white line disease (WLD), in particular Midla et al. (1998) and Fitzgerald et al., (2000). The mode of action of biotin in preventing WLD lameness is that biotin strengthens the white line by strengthening the extra- 
cellular cement of the white line horn tissues (Mülling et al., 1999).

In 1997, the first within-farm, randomized control trial to investigate the impact of biotin supplementation of dairy cattle was conducted. The study lasted for 18 mo and 900 cattle from five commercial dairy farms in the UK were enrolled (Hedges et al., 2001). In each herd cattle were managed as a single group, with half the cattle receiving $20 \mathrm{mg} / \mathrm{d}$ supplementary dietary biotin. The key results were that the overall incidence of lameness was 68.9 per 100 cow years with a range of 31.6 to 111.5 by farm. The incidence of WLD lameness was 12.7 per 100 cow years. It was the second most common cause of lameness. Cattle supplemented with biotin had a reduced risk of WLD to approximately $60 \%$ of that of nonsupplemented animals, with a hazard ratio (HR) of 0.57. Hedges et al. (2001) also reported that the risk of WLD increased with increasing parity but that study did not examine the effect of biotin supplementation in different parities nor the effect of duration of supplementation on the risk of WLD. Those questions are considered in more detail in the current study.

\section{MATERIALS AND METHODS}

\section{Data Source}

The data came from the same field trial of Hedges et al. (2001). Cattle entered and left farms in that study during the course of the investigation, and, as a result, some animals were supplemented with biotin for $18 \mathrm{mo}$ and some for as little as 3 mo. Cattle of all ages were included in the study. Biotin was fed orally to all cattle: milking cows were given a $20-\mathrm{ml}$ liquid dose containing $10 \mathrm{mg}$ of biotin twice a day on their feed in the milking parlor. Dry cows and heifers were fed $20 \mathrm{mg} / \mathrm{d}$ in 0.5 $\mathrm{kg}$ of concentrate feed. Cattle were matched on expected calving date and cows and heifers were stratified so that approximately even numbers within each age group received biotin supplement. Cattle were then assigned randomly to receive biotin supplementation or not. White line disease lameness was recorded when the examining veterinarian considered that a white line disease lesion was the cause of lameness.

All data were entered into a database (Microsoft Access) and checked for errors.

\section{Data Analyses}

All the data from the five farms that participated in this intervention study were used in this analysis. The occurrence of WLD lameness varied considerably by farm (Hedges et al., 2001). It was particularly low (five cases) on farm 1 , where supplementation was not given to cattle consistently each day (Hedges et al., 2001), but for completeness those data were included. Where possible, farm of origin, and, therefore, the accuracy of supplementation, was controlled for by forcing farm of origin into the analysis. Only WLD lameness that occurred after calving was analyzed, and repeat diagnoses of WLD in the same animal were excluded from the analyses. Where cows had more than one calf in the study, the first calving event was included in this analysis. Primiparous cows were defined as those that were in their first lactation after their first calving event.

To investigate the impact of duration of supplementation, the cattle were categorized into time in the trial in months, and cattle supplemented with biotin were compared with those not supplemented to identify when biotin affected the incidence of WLD. Kaplan-Meier survival graphs of the hazards were plotted for supplemented and nonsupplemented cattle.

Time to event or survival analysis (Collett, 1994) was used to investigate the impact of parity and duration of biotin supplementation on WLD. The event was the time from entering the study to the day of diagnosis of WLD. The effects of farm, parity, and duration of supplementation were tested in a forward stepwise Cox proportional hazards regression analysis (Collett, 1994) with a likelihood ratio chi square test (LRS $\chi^{2}$ ) significance level of $P \leq 0.05$, using EGRET 2.0 (Cytel Software Corporation, Cambridge, MA).

Hazard ratios were used to assess the impact of biotin supplementation. An HR $>1$ defines an increased risk of developing WLD, whereas $\mathrm{HR}<1$ indicates a reduced risk of developing WLD. Confidence intervals of $95 \%$ that include unity indicate no significant association between biotin supplementation and lameness incidence, given a type I error of $5 \%$. The goodness of fit of the models' assumptions was checked.

\section{RESULTS}

The overall incidence of WLD was significantly lower in cows supplemented with biotin compared with those not supplemented (Table 1). The incidence of WLD lameness was very low (2 cases/100 cow years) in primiparous cattle and increased with increasing parity to over 20 cases/100 cow years (Tables 1 and 2). When biotin supplementation was considered by parity (Table 2), there was no significant effect of supplementation in first-parity animals. There was evidence for a trend in reduction in the incidence of WLD between supplemented and nonsupplemented cattle in parities 2 and 3 (Table 2 and Figure 1). There was a significant reduction in WLD in supplemented cattle above parity three (Table 2). The strongest association between biotin and reduction in WLD was seen in cows above parity five 
Table 1. Cases $/ 100$ cow years (95\% confidence intervals) of white line disease lameness for primiparous and multiparous cows, stratified by biotin supplementation.

\begin{tabular}{llcl}
\hline Parity & Biotin supplemented & Not supplemented & $\chi^{2} P$ \\
\hline Primiparous & $3.04(0.0$ to 6.5$)$ & $1.93(0.0$ to 4.6$)$ & $>0.05$ \\
Multiparous & $8.48(5.8$ to 11.2$)$ & $15.48(11.6$ to 19.3$)$ & $<0.05$ \\
\hline
\end{tabular}

$\chi^{2} P=$ Chi-squared significance probability value, comparing supplemented and nonsupplemented cattle within parity group.

$(\mathrm{HR}=0.39)$ (Table 2). This is illustrated in the Kaplan Meier plots (Figure 1).

The duration of supplementation was considered for three groups of cattle: primiparous, multiparous and, because of the results above, cattle above parity three (Table 3). Reduced risk (lower HR; confidence intervals did not include unity) of WLD lameness was evident and significant $(P \leq 0.01)$ in all categories except primiparous cows for cattle that were supplemented with biotin for at least 6 mo.

The results from the current study indicate that multiparous cattle supplemented with $20 \mathrm{mg} / \mathrm{d}$ biotin have reduced risk of WLD lameness. The impact of biotin supplementation increased as duration of supplementation increased but only in multiparous cattle. For multiparous cattle supplemented with $20 \mathrm{mg}$ of biotin per day for at least 6 mo, there was about a $40 \%$ reduction in WLD lameness, compared with contemporary untreated cows.

\section{DISCUSSION}

There are two key areas for discussion. Firstly, multiparous cattle appear more responsive to biotin supplementation and secondly, biotin supplementation had a significant impact once cattle had been supplemented for at least 6 mo.

\section{Biotin Supplementation and Age}

White line disease was rare in primiparous cattle and increased in occurrence with increasing parity. In this study, a significant impact of biotin occurred in cattle $>$ parity 3 , but there was a trend for a positive effect of biotin supplementation in cows of parities 2 and 3 . These older cattle are no longer growing physically. Clinical WLD may occur in these cattle because of nutritional imbalances. Previous work indicates that this may include high levels of concentrate including starch/ corn or low concentrations of fiber, creating an acidic rumen, which alters the ruminal flora and in turn leads to reduced synthesis of microbial biotin (Davidson and Elliot, 1993; Abel et al., 2001). High producing cows are more likely to become lame (Barkema et al., 1994; Green et al., 2002). White line disease lameness may also occur in older cattle as a reoccurrence of disease from an earlier lactation (Hirst et al., 2002). Biotin is known to increase the rate of healing and to reduce the occurrence of white line lesions (Midla et al., 1998), it may therefore reduce WLD lameness by strengthening the hoof horn junction of the white line in these predisposed older cattle.

The effect of biotin was not evident in preventing WLD in primiparous cattle. This may be because fewer younger cows became lame, so there was insufficient power to detect a significant impact of biotin supplementation. However, it may indicate a different etiology for WLD lameness in primiparous cattle. Evidence for this comes from a study by Hedges et al. (2002) who reported that biotin supplementation of cattle in their first or second parity had no apparent effect on the tensile strength of the white line. In contrast, Midla et al. (1998), studied lesions rather than lameness and

Table 2. Cox proportional hazard survival analysis of the association between white line disease and biotin supplementation for supplemented and nonsupplemented cows (controlled for farm). ${ }^{1}$

\begin{tabular}{|c|c|c|c|c|c|c|c|}
\hline & & No biotin & & & & & \\
\hline Parity & No. cows & no. $(\%)$ & $\beta$ & s.e. & HR & CI & $\operatorname{LRS} \chi^{2}$ \\
\hline 1 & 231 & $2(1.7)$ & 0.44 & 0.91 & 1.55 & $0.26-9.25$ & 0.63 \\
\hline $2+3$ & 365 & $18(10.2)$ & -0.59 & 0.38 & 0.55 & $0.26-1.17$ & 0.12 \\
\hline $4+5$ & 211 & 23 (21.1) & -0.75 & 0.37 & 0.47 & $0.23-0.97$ & 0.04 \\
\hline$>5$ & 91 & $21(47.7)$ & -0.95 & 0.37 & 0.39 & $0.19-0.80$ & 0.01 \\
\hline
\end{tabular}

${ }^{1}$ Parity $=$ parity at end of trial, no. $=$ number of cattle, biotin $=$ Number and percent of cattle with white line disease that received biotin, no biotin $=$ Number and percent of cattle with white line disease that did not receive biotin supplement, $\beta=$ coefficient, s.e. $=$ standard error, $\mathrm{HR}=$ Hazard Ratio, $\mathrm{CI}=95 \%$ confidence limits, LRS $\chi^{2}=$ likelihood ratio statistic chi-square value 


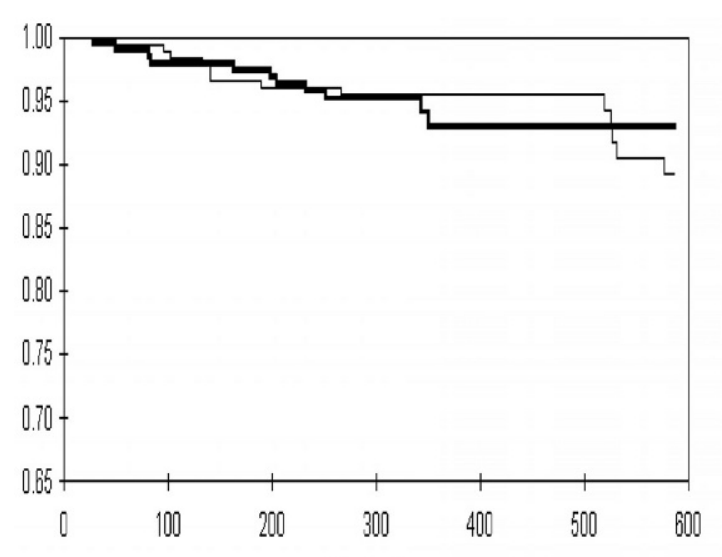

a) Primiparous cows, NB. $Y$ axis starts at 0.65

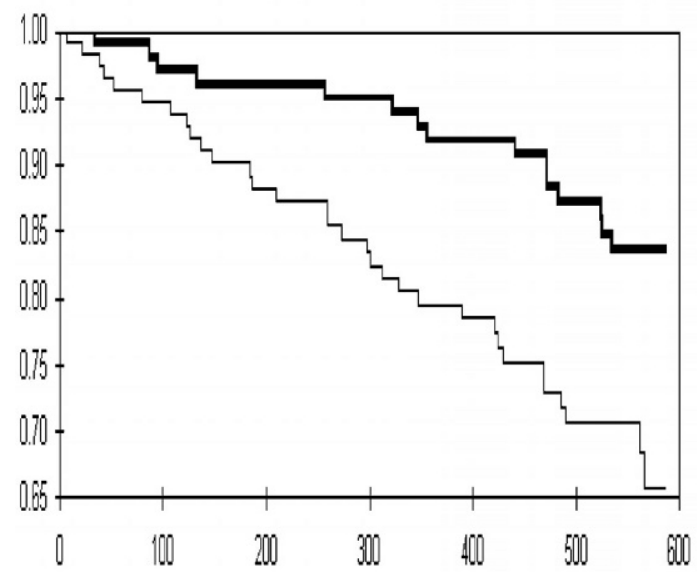

c) Parity 4 and 5 cows, NB. $Y$ axis starts at 0.65

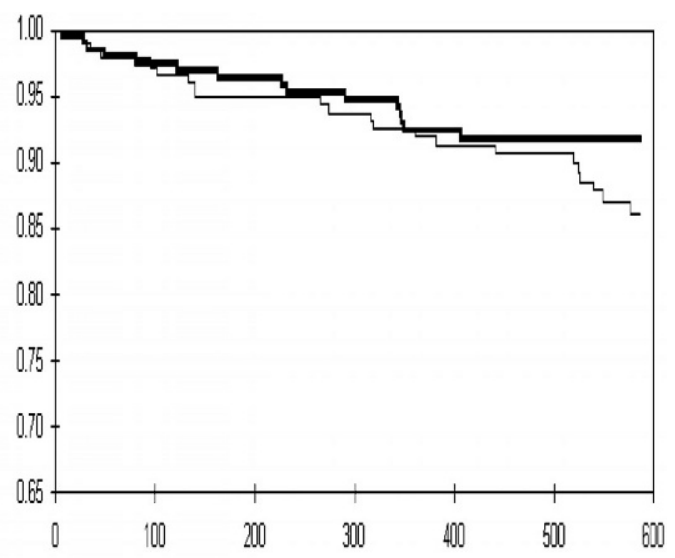

b) Parity 2 and 3 cows, NB. Y axis starts at 0.65

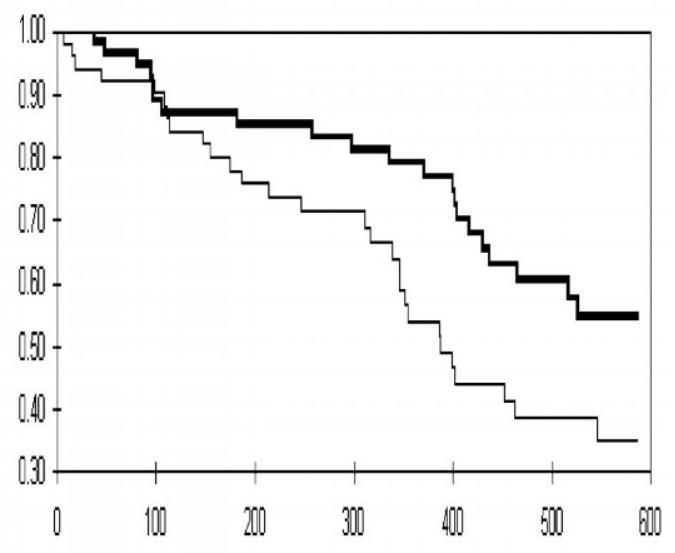

d) Cows above parity 5 , NB. Y axis starts at 0.30

Figure 1. Kaplan-Meier survival plots for white line disease of biotin supplemented, (thick line) and nonsupplemented (thin line) cows, $\mathrm{x}$ axis $=$ time in days, $\mathrm{Y}$ axis $=$ survival function.

did detect a significant reduction in WLD lesions in primiparous cattle. Biotin may therefore have an effect on the quality of the white line, but because these cattle are at inherently lower risk of WLD lameness, this would not manifest as a significant clinical improvement unless a very large, and therefore statistically powerful study were performed.

\section{Duration of Supplementation}

The HR for the impact of supplementation decreased as cattle were supplemented for a longer period, indicating an increasingly reduced risk of WLD lameness with increasing period of supplementation. Cattle supplemented with $20 \mathrm{mg} / \mathrm{d}$ biotin for more than $6 \mathrm{mo}$ had markedly less risk of WLD than cattle supplemented for a shorter period. A lack of significant impact of biotin supplementation on WLD lameness in cattle supplemented for less than 6 mo may either be due to low statistical power or it may be because at least 6 mo of supplementation is required. Whichever of these is true, the decreasing HR indicates that supplementation for $>6$ mo provides the greatest benefit in reducing WLD lameness. Some authors have reported a response to supplementation in reduced WLD lesions after 2 to 3 mo (Hoblet et al., 2002). Our study investigated lame cows, and this may be why there is a difference in observed time to effect. We do not have data on the effect of removing biotin from the diet, but because it is a water-soluble compound, it is unlikely that there would be permanent benefit without continuous supplementation. 
Table 3. Cox proportional hazard survival analysis of the association between white line disease lameness and duration in trial for supplemented and nonsupplemented cattle by parity. ${ }^{1}$

\begin{tabular}{|c|c|c|c|c|c|c|c|c|c|}
\hline $\begin{array}{l}\text { Mo. in } \\
\text { trial }\end{array}$ & $\begin{array}{l}\text { No. } \\
\text { cows }\end{array}$ & $\begin{array}{l}\text { Biotin } \\
\text { no. } \%\end{array}$ & $\begin{array}{l}\text { No biotin } \\
\text { no. } \%\end{array}$ & Cont. & $\beta$ & s.e & HR & CI & $\operatorname{LRS} \chi^{2}$ \\
\hline \multicolumn{10}{|c|}{ Primiparous cows } \\
\hline 1 to 6 & 12 & $0(0)$ & $2(16.7)$ & $\ldots$ & & & & & \\
\hline$>6$ & 219 & $2(0.9)$ & $1(0.5)$ & $\ldots$ & -0.66 & 0.52 & 1.23 & $0.05-5.71$ & 0.59 \\
\hline \multicolumn{10}{|c|}{ Multiparous cows } \\
\hline 1 to 3 & 55 & $9(16.4)$ & $13(23.6)$ & $\mathrm{F}$ & -0.49 & 0.61 & 0.44 & $0.26-1.44$ & 0.26 \\
\hline 4 to 6 & 36 & $6(16.7)$ & $14(38.9)$ & & -0.52 & 0.60 & 0.52 & $0.21-1.66$ & 0.32 \\
\hline$>6$ & 576 & $21(3.6)$ & $35(6.1)$ & $\mathrm{F}, \mathrm{Pa}$ & -0.82 & 0.44 & 0.28 & $0.25-0.77$ & $<0.01$ \\
\hline \multicolumn{10}{|c|}{ Cows above parity 3} \\
\hline 1 to 3 & 33 & $5(15.2)$ & $9(27.3)$ & . & -0.64 & 0.52 & 0.57 & $0.17-1.60$ & 0.26 \\
\hline 4 to 6 & 24 & $5(20.1)$ & $10(41.7)$ & & -0.19 & 0.83 & 0.59 & $0.26-2.65$ & 0.75 \\
\hline$>6$ & 245 & $15(6.1)$ & $25(10.2)$ & $\mathrm{F}, \mathrm{Pa}$ & -0.86 & 0.42 & 0.34 & $0.22-0.83$ & 0.01 \\
\hline
\end{tabular}

${ }^{1} \mathrm{Mo}=$ mo in trial, No. = number of cattle, Biotin $=$ number and percent of cattle with white line disease that received biotin, No biotin $=$ number and percent of cattle with white line disease that did not receive biotin supplement, Cont. $=$ controlling for $\mathrm{F}=$ farm, $\mathrm{Pa}=$ parity, $-=$ nothing, $\beta=$ coefficient, s.e. $=$ standard error, $\mathrm{HR}=$ hazard ratio, $\mathrm{CI}=95 \%$ confidence limits, LRS $\chi^{2}=$ likelihood ratio statistic Chi-square value.

\section{The Impact of Biotin Supplementation on the Health, Welfare, and Productivity of Cattle}

The results come from a within-farm intervention study on five farms in Great Britain and may not be accurately generalized to all farms. However, there is empirical evidence that lameness increases with parity (Hirst et al., 2002) and a within-farm comparison is a very robust approach to detect the impact of interventions. Lameness is an important cause of poor health, welfare, and productivity in dairy cattle (Kossaibati and Esslemont, 1995, 2000; FAWC, 1997) and the findings from this study indicate that biotin is most beneficial in parities where WLD is most prevalent, i.e., cattle above third parity. These cows are at the height of their milk production, and losses in milk yield due to lameness can be high. In our study, the total cost of WLD per 100 cow years may be estimated at US $\$ 4500$ ( $\$ 3000$ ), considering an incidence of 15.5 cases per 100 cow years and the total cost per case of US $\$ 290$ ( $£ 180$ ) (Kossaibati and Esslemont, 2000 plus Green et al., 2002). Because biotin supplementation can reduce WLD in multiparous cows by approximately $45 \%$, costs of nearly US $\$ 2025$ ( $£ 1350$ ) could be saved per 100 cows per year, less the cost of biotin supplementation. In other studies, biotin supplementation has also had a positive benefit on milk SCC and milk yield (Midla et al., 1998; Fitzgerald et al., 2000; Zimmerly and Weiss, 2001). These may also be considered in estimates of the positive effect of biotin supplementation on health, productivity, and therefore profitability.

In our study, it was not possible to investigate the impact of biotin supplementation before calving because nearly all supplemented cattle and heifers were fed $20 \mathrm{mg} / \mathrm{d}$ biotin for at least $3 \mathrm{mo}$. Hoblet et al. (2002) reported better white line health (assessed by lesions) in primiparous cows supplemented with $20 \mathrm{mg} / \mathrm{d}$ throughout pregnancy compared with cows that were supplemented after calving. Because the highest incidence of lameness occurred in early lactation (Leach et al., 1997; Fitzgerald et al., 2000; Hedges, 2001), supplementation of biotin before calving may reduce the risk of WLD by strengthening the weight bearing horn 4 to 5 mo before the critical period for development of disease. This time from the beginning of the dry period until the critical time for WLD lameness ensures that the total depth of coronary horn has been supplemented with biotin for 4 to 5 mo (Schmid and Geyer, 1994; Lischer and Ossent, 2000).

\section{CONCLUSIONS}

There is evidence from commercial farm studies and laboratory investigations to conclude that supplemental dietary biotin reduces clinical white line disease (Hedges et al., 2001), reduces horn lesions, and improves horn quality (Distl and Schmid, 1994), and that it does so by strengthening the intercellular cementing material between keratinocytes (Mülling et al., 1999). However, whereas other studies have reported a reduction in lesions after 2 to 3 mo of supplementation (Hoblet et al., 2002), we found that 6 mo of biotin supplementation was required to see a significant reduction in WLD lameness. In multiparous cows, biotin supplementation was effective at preventing WLD at a rate of about $45 \%$ reduction in disease. The impact of this for both animal welfare and farm economics is considerable.

\section{ACKNOWLEDGMENTS}

We are grateful to the farmers and veterinarians who made the data collection possible. 


\section{REFERENCES}

Abel H. J., I. Immig, C. da Costa Gomez, and W. Steinberg. 2001. Effect of increasing dietary concentrate levels on microbial biotin metabolism in the artificial rumen simulation system (RUSITEC). Arch. Anim. Nutr. 55:371-376.

Barkema, H. W., J. D. Westrik, K. A. S. van Keulen, Y. H. Schukken, and A. Brand. 1994. The effects of lameness on reproductive performance, milk production and culling in Dutch Dairy Farms. Prev. Vet. Med. 20:249-259.

Clarkson, M. J., D. Y. Downham., W. B. Faull, J. W. Hughes, F. J. Manson, J. B. Merritt, R. D. Murray, W. B. Russell, J. E. Sutherst, and W. R Ward. 1996. Incidence and prevalence of lameness in dairy cattle. Vet. Rec. 138:563-567.

Collett D. 1994. Modelling Survival Data in Medical Research. Chapman \& Hall/CRC, London.

Davidson, T. M., and R. Elliot. 1993. Response of lactating cows to grain based concentrate in Northern Australia. Trop. Grassl. Res. 27:229-237.

Distl, O., and D. Schmid. 1994. The influence of biotin supplementation on the conformation, hardness and health of claws of dairy cows. Tierärztliche Umschau. 49:581-584.

Distl, O. 1995. Genetic improvement of traits of feet and leg as well as claw soundness in cattle. Züchtungskunde 67:438-448.

FAWC. 1997. Report on the welfare of dairy cattle. Farm Animal Welfare Council. Home Office publications, London.

Fitzgerald, T., B. W. Norton, R. Elliot, H. Podlich, and O. L. Svendsen. 2000. The influence of long-term supplementation with biotin on the prevention of lameness in pasture fed dairy cows. J. Dairy Sci. 83:338-344.

Green L. E., V. J. Hedges, Y. H. Schukken, R. W. Blowey, and A. J. Packington. 2002. The impact of clinical lameness on the milk yield of dairy cows. J. Dairy Sci. 85:2250-2256.

Hedges, V. 2001. Epidemiological and biomechanical studies into the role of biotin supplementation on lameness in dairy cows. Dissertation, University of Bristol, UK.

Hedges, V., R. W. Blowey, A. J. Packington, C. J. O'Callaghan, and L. E. Green. 2001. A longitudinal field trial of the effect of biotin supplementation on lameness in dairy cows. J. Dairy Sci. 84:1969-1975.

Hedges, V. J., L. E. Green, R. W. Blowey, A. J. Packington, and R. Bonser. 2002. Tensile strength testing of the white line in the claw of dairy cows supplemented with biotin. Pages $167-170$ in
XII International Symposium on Lameness in ruminants. Orlando, FL.

Hirst, W. M., N. P. French, R. D. Murray, and W. R. Ward. 2002. A mixed-effects time-to-event analysis of the relationship between first-lactation lameness and subsequent lameness in dairy cows in the UK. Prev. Vet. Med. 54:191-201.

Hoblet, K., W. Weiss, D. Anderson, and M. Moeschberger. 2002. Effect of oral biotin supplementation on hoof health in Holstein heifers during gestation and early lactation. Pages 253-255 in XII International Symposium on Lameness in Ruminants. Orlando, FL.

Kossaibati, M. A., and R. J. Esslemont. 1995. Wastage in dairy herds. DAISY Report No. 4. The University of Reading, UK. Kossaibati, M. A., and R. J. Esslemont. 2000. The incidence of lameness in 50 dairy herds in England. Pages 160-162 in XI International Symposium on Disorders of the Ruminant Digit. Parma, Italy.

Leach, K. A., D. N. Logue, S. A. Kempson, J. E. Offer, H. E. Ternent, and J. M. Randall. 1997. Claw lesions in dairy cattle: Development of sole and white line hemorrhages during the first lactation. Vet. J. 154:215-225.

Lischer, C. J., and P. Ossent. 2000. Sole ulcers in dairy cattlewhat's new about an old disease? Pages 46-48 in XI International Symposium on Disorders of the Ruminant Digit. Parma, Italy.

Midla, L. T., K. H. Hoblet, W. P. Weiss, and M. L. Moeschberger. 1998. Supplemental dietary biotin for prevention of lesions associated with aseptic subclinical laminitis (pododermatitis aseptica diffusa) in primiparous cows. Am. J. Vet. Res. 59(Suppl. 6):733-738.

Mülling, C. K. W., H. H. Braguella, S. Reese, K. D. Budras, and W. Steinberg. 1999. How structures in bovine hoof epidermis are influenced by nutritional factors. Anat. Histol. Embryol. 28:103-108.

Schmid, M., and T. H. Geyer 1994. Effect of biotin on the quality of the claw horn in dairy cows. Pages 15-19 in 20th Congress Euro. Assoc. Vet. Anatomists, Zürich.

Warnick, L. D., D. Janssen, C. L. Guard, Y. T. Grohn. 2001. The effect of lameness on milk production in dairy cows. J. Dairy Sci. 84:498-506.

Wells, S. J., A. M. Trent, and W. E. Marsh. 1993. Prevalence and severity of lameness in lactating dairy cows in a sample of Minnesota and Wisconsin herds. J. Am. Vet. Med. Assoc. 202:78-82.

Zimmerly, C. A., and W. P. Weiss. 2001. Effects of supplemental dietary biotin on performance of Holstein cows during early lactation. J. Dairy Sci. 84:498-506. 